\title{
Relationship between primitive reflexes and severity in Parkinson's disease
}

\author{
STEVEN J HUBER, GEORGE W PAULSON \\ From the Ohio State University College of Medicine, Department of Neurology. Columbus, Ohio, USA
}

SUMMARY The reliability of primitive reflexes as monitors of dementia, depression, and severity of Parkinson's disease were studied. The results indicated that the proportion of certain reflexes increased with severity of disease and cognitive impairment, but no relationship was seen between any of the reflexes and degree of depression.

Release reflexes, primitive reflexes, embryonic reflexes, or cortical disinhibition responses are among the labels used for several reflexes which are common in fetal or infant life, become less apparent in young adults, and then are seen again in aged patients or in patients with cortical deterioration. ${ }^{1}$ Representatives of this heterogeneous group of reflexes include the grasp, palmomental, snout or sucking, corneomandibular, and glabellar reflexes, all of which have an extensive bibliography in neurology. It is not now accepted, if it ever was, that the degree of cortical deterioration correlates well with the presence or intensity of these reflexes, ${ }^{23}$ nor is any one of them diagnostic of a specific disease. Several of the primitive reflexes are prominent in patients with Parkinson's disease. This study examined the relationship between these reflexes and the dementia, depression, and severity of clinical symptoms in patients with $\mathrm{Par}$ kinson's disease.

\section{Patients and methods}

Forty-eight consecutive patients with idiopathic Parkinson's disease participated in the study. All patients were receiving medication to alleviate clinical symptoms, but none had undergone thalamotomy. This group had a mean age of 65.7 years and a range of 38 to 86 years.

Address for reprint requests: Dr Steven J Huber, Department of Neurology, 439 Means Hall, 1655 Upham Dr, Colombus, Ohio, 43210, USA.

Received 1 October 1985 and in revised form 19 February 1986. Accepted 24 February 1986
Severity of disease was rated by the Hoehn and Yahr scale. ${ }^{4}$ Twenty-seven patients were classed as Stage I or II and twenty-one patients into Stages III or IV. Depression was assessed by a self-rating scale. ${ }^{5}$ Each patient completed the questionnaire which provides a quantified estimate of depressive symptoms. In the original report on this depression scale, ${ }^{5}$ normal controls had a mean raw score of 33 with a range of 25-43, and we used this range as a measure of normality with higher numbers indicative of depression. According to this criterion, 24 patients were and 24 patients were not depressed. Severity of dementia was assessed by the Mini-Mental State Exam. ${ }^{6}$ This brief evaluation of mental function is well accepted and correlates well with more extensive intellectual assessment such as the Wechsler Adult Intelligence Scale. ${ }^{67}$ Our previous research using normal controls matched for age and educational background found that this group had a range of $27-30$ on the MiniMental State Exam. Therefore, we used 27 as a cut-off point to distinguish our Parkinson's disease patients for severity of dementia. Twenty-two patients fell within the normal range and sixteen patients had evidence of intellectual decline.

Grasp, palmomental, corneomandibular, snout or sucking, and glabellar reflexes were examined in each patient. ${ }^{8}$ Grasp reflex was checked by a firm stroking movement across the palm, and if the patient clutched the examiners hand a positive response was recorded. Palmomental reflex was elicited by a quick scratch applied to the thenar area with the positive response observed in the ipsilateral mentalis muscle. Corneomandibular reflex was elicited by a quick touch to the cornea with a cotton point and a positive response was a chin movement in the opposite direction. To produce a snout reflex the philtrum was stimulated with noticeable puckering of the lips as the positive response. The glabellar tap sign was considered positive when ten consecutive taps applied to the glabellar area led to continued blinking. 
Table Incidence of reflex response as a function of severity of Parkinson's disease

\begin{tabular}{|c|c|c|c|}
\hline & \multicolumn{3}{|l|}{ Stage of disease } \\
\hline & $\begin{array}{l}1 \text { and } 2(n=27) \\
\% \text { Present }\end{array}$ & $\begin{array}{l}3 \text { and } 4(n=21) \\
\% \text { Present }\end{array}$ & Difference \\
\hline $\begin{array}{l}\text { Grasp } \\
\text { Corneomandibular } \\
\text { Snout } \\
\text { Palmomental } \\
\text { Glabellar }\end{array}$ & $\begin{array}{r}0 \\
0 \\
11 \\
37 \\
63\end{array}$ & $\begin{array}{l}10 \\
57 \\
14 \\
67 \\
86\end{array}$ & $\begin{array}{l}+10, \mathrm{NS} \\
+57, \mathrm{p}<0.01 \\
+3, \mathrm{NS} \\
+30, \mathrm{p}<0.05 \\
+23, \mathrm{NS}\end{array}$ \\
\hline
\end{tabular}

Incidence of reflex response as a function of severity of dementia in patients with Parkinson's disease

\begin{tabular}{|c|c|c|}
\hline \multirow[b]{2}{*}{$\begin{array}{l}\text { Grasp } \\
\text { Corneomandibular } \\
\text { Snout } \\
\text { Palmomental } \\
\text { Glabellar }\end{array}$} & \multicolumn{2}{|l|}{ Mini-Mental State scores } \\
\hline & $\begin{array}{l}27-30(n=32, \bar{x}=28 \cdot 1) \\
\% \text { Present } \\
3 \\
13 \\
6 \\
38 \\
66\end{array}$ & $\begin{array}{ll}26 \text { - } 9(n=16, \bar{x}=22 \cdot 0) \\
\% \text { Diffesent } \\
6 \\
6 \\
50 & +3, \mathrm{NS} \\
31 & +37, \mathrm{p}<0.01 \\
69 & +25, \mathrm{p}<0.05 \\
81 & +31, \mathrm{p}<0.05 \\
& +15, \mathrm{NS}\end{array}$ \\
\hline
\end{tabular}

Incidence of reflex response as a function of depression in patients with Parkinson's disease

\begin{tabular}{|c|c|c|}
\hline \multirow[b]{2}{*}{$\begin{array}{l}\text { Grasp } \\
\text { Corneomandibular } \\
\text { Snout } \\
\text { Palmomental } \\
\text { Glabellar }\end{array}$} & \multicolumn{2}{|l|}{ Zung Depression Scale } \\
\hline & $\begin{array}{l}20-43(n=24, x=34 \cdot 7) \\
\% \text { Present } \\
04 \\
21 \\
08 \\
42 \\
63\end{array}$ & $\begin{array}{ll}44-73(n=24, \bar{x}=51 \cdot 8) \\
\% \text { Present } \\
04 & \text { Differences } \\
29 & + \text { NS } \\
21 & +13, \text { NS } \\
58 & +16, \text { NS } \\
79 & +16, \text { NS }\end{array}$ \\
\hline
\end{tabular}

\section{Results}

Since the likelihood of these reflexes increase with age, ${ }^{7}$ the ages of our patient groups divided according to severity of disease, dementia, and depression were examined. There were no age differences between the groups as a function of disease severity $(66 \cdot 1$ vs $65 \cdot 1)$, $\mathrm{t}(46)=0.33$, dementia $(64.9$ vs 67$), \mathrm{t}(46)=0.63$, or depression $(63.3$ vs 68$), t(46)=1 \cdot 6$. Therefore, any differences in terms of the proportion of positive reflexes as a function of disease, dementia, or depression severity is not confounded by the age factor.

As shown in the table, the likelihood of certain reflexes being present does increase as the severity of Parkinson's disease increases. The proportion of patients with corneomandibular, $\mathrm{t}(46)=4.52, \mathrm{p}<$ 0.01 , and palmomental reflexes, $t(46)=2.06, p<$ 0.05 , increased significantly when patients were more impaired by disease. The table also illustrates the relationship between the occurrence of these reflexes and severity of dementia. The proportion of positive corneomandibular, $\mathrm{t}(46)=2.8, \mathrm{p}<0.01$, palmomental, $\mathrm{t}(46)=2 \cdot 18, \mathrm{p}<0.05$ and snout reflexes, $\mathrm{t}(46)=2.28, \mathrm{p}<0.05$, increased significantly with cognitive decline. In the table is shown the relationship between these reflexes and depression in patients with Parkinson's disease. As can be seen in the table, none of these reflexes were more prominent as a function of depression.

\section{Discussion}

This research examined whether several primitive reflexes known to be common in patients with Parkinson's disease reflect severity of disease, dementia, or depression. The results suggest that the corneomandibular and palmomental reflexes are more prominent with advancing disease, and these two reflexes along with the snout reflex are sensitive to intellectual decline. None of the reflexes was more common when depression was severe.

Most neurologists would not expect an exact or predictable correlation between these reflexes and the severity of Parkinson's disease, even though the reflexes are often noted in patients with Parkinson's disease. The palmomental reflex was first described in amyotrophic lateral sclerosis, ${ }^{9}$ but is probably more common in Parkinson's disease. The corneomandibular reflex can be present in coma or in infancy, but is uncommon in healthy alert adults. 
Grasp reflex, particularly when unilateral, traditionally correlates with damage to the contralateral frontal lobe, but there is of course no comparison between the value of this test and the reliability of either CT scan or MRI for true localisation. Klawans and Paulson ${ }^{10}$ reported that the glabellar tap sign may be the best monitor of severity in Parkinson's disease. Our results found that this reflex may indeed be the most common one seen in patients with Parkinson's disease, but the corneomandibular and palmomental reflexes may be more sensitive to disease severity.

Our research and that of others suggest that a snout reflex, ${ }^{211}$ a palmomental reflex, ${ }^{12}$ and the corneomandibular reflex are more common in the presence of dementia. However, Pearce et al,,$^{13}$ have clearly suggested that the presence of these reflexes is dependent upon the extent of cerebral degeneration but is not specific to any particular pathological feature. Further, Tweedy et al, ${ }^{2}$ and Jenkyn et al ${ }^{11}$ have pointed out that primitive reflexes are not precise indicators of dementia. The reflexes can fatigue quickly and there is more than one way to elicit them. For example, the vigor with which the lip is tapped to elicit a snout reflex can influence the result.

None of these reflexes take long to perform and can be interesting to observe. Even if not a crucial part of the examination for dementia, they do retain some theoretical interest. There may be other neurologic phenomena of childhood that reappear in old age or with dementia. There may be unexplored relationships between frequency of blinking and the glabellar tests, or between both and the Parkinsonian stare. Pointing as done by either child or adult may use the same central circuits as are employed in the grasp reflex. There certainly can be a modest linkage between the presence of these reflexes and the degree of cognitive impairment as well as a link between these reflexes and advancing age, raising interesting philosophical questions regarding inhibition, old age, and cortical function.

This work was supported in part by a grant from the United Parkinson Foundation.

\section{References}

${ }^{1}$ Paulson GW, Gottlieb G. Development reflexes: The reappearance of fetal and neonatal reflexes in aged patients. Brain 1968;91:37-52.

${ }^{2}$ Tweedy J, Reding M, Garcia C, Schulman P, Dentsch G, Antin S. Significance of cortical disinhibition. Neurology 1982;32:169-73.

${ }^{3}$ Moylan JJ, Saldias CA. Developmental reflexes and cortical atrophy. Ann Neurol 1979;5:499-500.

${ }^{4}$ Hoehn MM, Yahr MD. Parkinsonism: Onset, progression and mortality. Neurology 1967;17:427-42.

${ }^{5}$ Zung WWK. A self-rating depression scale. Arch Gen Psychiatry 1965;12:63-70.

${ }^{6}$ Folstein MF, Folstein SE, McHugh PR. "Mini-Mental State": A practical method for grading the mental state of patients for the clinician. $J$ Psychiatric Res 1975;12:189-98.

${ }^{7}$ McHugh PR, Folstein MF. Psychopathology of dementia: implications for neuropathology. In: Katzmann R, ed. Congenital and Acquired Cognitive Disorders. New York: Raven Press, 1979:17-30.

${ }^{8}$ Paulson GW. The neurological examination in dementia. In: Wells CE, ed. Dementia. Philadelphia: Davis, 1978:13-34.

${ }^{9}$ Blake JR, Kunkle EC. The Palmomental Reflex. Arch Neurol 1951;65:337-45.

${ }^{10}$ Klawans HL, Paulson GW. Primitive reflexes in parkinsonism. Conf Neurol 1971;33:25-32.

11 Jenkyn LR, Walsh DB, Culver CM, Reeves AG. Clinical signs in diffuse cerebral dysfunction. $J$ Neurol Neurosurg Psychiatry 1977;40:956-66.

12 Basavaraju NG, Silverstone FA, Libow LS, Paraskevas $K$. Primitive reflexes and perceptual sensory tests in the elderly-their usefulness in dementia. J Chron Dis 1981;34:367-77.

${ }^{13}$ Pearce J, Aziz H, Gallagher JC. Primitive reflex activity in primary and symptomatic parkinsonism. $J$ Neurol Neurosurg Psychiatry 1968;31:501-8. 